\title{
\#FollowMe: An investigation into the relationship between social media behaviors and online harassment among adolescents
}

\author{
Tabrina M. Bratton ${ }^{1^{*}} \quad$ Robert D. Lytle ${ }^{1} \quad$ Heather K. Hudson ${ }^{2}$
}

\begin{abstract}
Social media is a relatively new global phenomenon. Virtual places provide criminogenic motivators like financial gain, access to suitable targets, and massive amounts of information all under one virtual roof. Additionally, social media sites host large amounts of people in one space, generating significant opportunities for victimization. Despite the Internet's theoretical relevance to understanding victimization, scholarly research into the effects of social media activity in victimization is scarce. Using data from the Pew Research Center, I investigated the relationship between Facebook use and online harassment among adolescents between 13 and 17 years of age. The results showed that an adolescent's behavior on Facebook contributed to the likelihood of experiencing online harassment. Additionally, parental monitoring of their adolescent's Facebook activity did not have a significant moderating effect on adolescents' risk of online harassment. This research contributed to the literature by identifying specific behaviors in adolescents that increase their risk of online harassment.
\end{abstract}

Keywords: social media, online harassment, cybervictimization, dyadic data, Facebook

\section{Introduction}

Cyberspace connects an estimated 8.4 billion "things" globally, including nearly one-half of the world's population (Bossler and Holt, 2009; Smith and Anderson, 2018). One of the most common activities for Internet users is logging onto a social networking site (SNS). These virtual communities allow people from around the world to network and connect with others regardless of time or space (Danah, 2011; Danah and Ellison, 2008; Haythornthwaite, 2005).

Interactions through SNSs have allowed young adults to build, maintain, and sustain relationships by organizing social gatherings and sharing experiences with friends and peers (Horstmanshof and Power, 2005). Despite the benefits of SNS participation, SNSs also create new methods for nefarious behaviors and increase the risk of online harassment (Dehue et al., 2008; Haythornthwaite, 2005; Oksanen and Keipi, 2013; Reyns et al., 2016; Ryan

Received: July 2, 2020; Accepted: September 4, 2020; Published: September 8, 2020

Correspondence to: Tabrina M. Bratton, Department of Criminal Justice, University of Arkansas at Little Rock, Arkansas 72204, USA; Email: tmbratton@ ualr.edu

${ }^{1}$ Department of Criminal Justice, University of Arkansas at Little Rock, Arkansas 72204 USA

Department of Health Sciences, University of Central Arkansas, Arkansas 72035, USA

Citation: Bratton TM, Lytle RD and Hudson HK. \#FollowMe: An investigation into the relationship between social media behaviors and online harassment among adolescents. Int $J$ Arts Humanit, 2020, 1(1): 16-27.

Copyright: (c) 2020 Tabrina M. Bratton, et al. This is an open access article distributed under the terms of the Creative Commons Attribution License, which permits unrestricted use, distribution, and reproduction in any medium, provided the original author and source are credited. and Xenos, 2011).

Though online harassment has been a persistent problem for adults (Duggan, 2017; Leukfeldt, 2014; Ngo and Paternoster, 2011; Reyns et al., 2011; Rife et al., 2013; Runions et al., 2017), adolescents remain the most common targets of cybervictimization (Moore et al., 2010; Marcum et al., 2014; O'Keeffe and Clarke-Pearson, 2011; Oksanen and Keipi, 2013; Sengupta and Chaudhuri, 2010; Smith et al., 2008; Tokunaga, 2010; Ybarra and Mitchell, 2008. Negative online experiences can adversely affect one's well-being and lead to deviance or victimization offline (Shaw et al., 2015; Valkenburg et al., 2006). For example, $25 \%$ of teenagers have had either a verbal or physical face-to-face confrontation due to an event that began online (Lenhart et al., 2011). Additionally, several cases of youth suicide have been linked to SNS participation (Hinduja and Patchin, 2011; Sullivan et al., 2015).

\section{The current study}

Research into online victimization has focused on various online platforms, including chat rooms, gaming websites, and SNSs. Despite the rising attention on online victimization, the number of studies that have examined the link between SNS-specific behaviors and online victimization remains relatively small (Leukfeldt, 2014; Moore et al., 2010; Oksanen and Keipi, 2013; Sengupta and Chaudhuri, 2010). The prevalence of online harassment, 
along with the popularity of SNSs among adolescents, calls for our continuing attention.

We contribute to the growing literature on SNS activity and online victimization by examining the influence of adolescent SNS behaviors, along with parental monitoring thereof, on online harassment experienced through one of the world's most popular SNSs - Facebook (Desilver et al., 2014). This study also builds upon two core criminological components from opportunity theory - target suitability and guardianship (Cohen and Felson, 1979). Thus, we also assessed a possible moderating effect of parental guardianship on the relationship between adolescent SNS activity and online harassment. We used dyadic data collected through the Pew Research Center's 2014 Teen Relationship Survey (TRS) to answer two research questions:

RQ1: What is the relationship between adolescents' SNS behavior and online harassment?

RQ2: What is the moderating effect of parents/legal guardians on the risk of online harassment?

\section{Literature review}

\subsection{Routine activities theory}

Cohen and Felson's (1979) Routine Activities Theory (RAT) grew out of a desire to predict when and where criminal events might occur in a given setting (i.e., opportunity). The necessary "ingredients" of criminal opportunity are defined in RAT as offender motivation, target suitability, and capable guardianship. More specifically, RAT proposes that criminal opportunity is present when a motivated offender has access to a suitable (i.e., attractive) target in the absence of people or technology that can interfere with the crime (i.e., guardians; Cohen and Felson, 1979). Though social environments have changed drastically since Cohen and Felson (1979) first introduced their theory, RAT continues to be one of the most useful explanations for crime among criminal justice scholars (Bossler and Holt, 2009).

Technological advancements have transformed the traditional constructs of crime, place, and time, which necessitates additional theoretical consideration to encompass our modern information-centric society. Modern conceptualizations of place now need to include cyberspace, where opportunities for offending have exponentially increased. Within the RAT framework, routine activities were originally defined as, "any recurrent and prevalent activities which provide for basic population and individual need...thus routine activities would include formalized work, as well as the provision of leisure, social interaction" (Cohen and Felson, 1979, p. 593). This definition of routine activities can also apply to cyberspace, such as engaging in social media or checking emails. To the degree that routine activities in online environments facilitates access to suitable targets in the absence of suitable guardians, RAT can prove useful as an explanation for criminal opportunity in cyberspace (Bossler Holt and May 2012; Choi, 2008; Holtfreter et al., 2008; Hutchings and Hayes, 2009; Kalia and Aleem, 2017; Mesch, 2009; Navarro and Jasinski, 2012; Reyns et al., 2011). For our study, RAT provides a useful theoretical framework in which to understand both the role of adolescent online behaviors and parental monitoring in one's risk of experiencing online harassment.

\subsection{SNS participation}

The growth and popularity of SNSs is partially attributed to the ability to form new social ties, maintain existing relationships, and share content with others (Danah, 2011; Livingstone, 2008). Although these behaviors are primary functions on SNSs, they have also been shown to predict cybervictimization (Bergman et al., 2011; Carpenter, 2012; Jelenchick et al., 2013; Mesch, 2009; Tandoc et al., 2015).

SNS profiles contain personal content, such as videos, pictures, information about one's identity and other various information (Dwyer et al., 2007; Mesch, 2009; Yardley and Wilson 2015), which adolescents freely share with others online (Dwyer et al., 2007; Madden et al., 2013). Although SNSs allow users to make their profiles private, privacy settings only prevent people outside of an individual's SNS network from accessing their information (Lenhart et al., 2011). Regardless, many SNS users do not take advantage of privacy settings (Lenhart et al., 2011).To build one's SNS network, users add and accept strangers to a list of contacts with access to the user's profile (O'Keeffe and Clarke-Pearson, 2011).

The average adolescent Facebook user has approximately 300 people in their network, $33 \%$, of whom they have never met in person (Madden et al., 2013). This is concerning given the finding that adolescents who accept friend requests from strangers unknowingly doubled their odds of unwanted contact, sexual advances, and cyberstalking victimization. Bossler and colleagues (2012) examined cybervictimization among adolescents in Kentucky and found that the more participants posted pictures online, sent pictures of themselves to someone they met online, and interacted with people they met online the more at risk they were. Sending photos to other SNS members could be a way of flirting or sexting. SNSs are commonly used for sexting among young adults (Hudson et al., 2014; Lenhart, 2009; The National Campaign, 
2009). While most sexting experiences were reported as positive and empowering, some sexting experiences have resulted in cybervictimization (Hudson et al., 2014). Relatedly,Sengupta and Chaudhuri (2010) found that adolescents who flirt on a SNS are more likely to experience online victimization.

For our study, this literature review led us to conclude that one's activity on SNSs informs one's risk of experiencing online harassment. More specifically, adolescents who casually share content, add strangers to their networks, and flirt online may, albeit unknowingly, increase their suitability as a target of online harassment. This conclusion informed our first two hypotheses:

H1. Online harassment will be more likely amongst those who have larger networks.

$\mathrm{H} 2$. Online harassment will be more likely amongst those who make friends through Facebook.

\subsection{Parental guardianship}

Parents have been well-documented to serve as effective guardians in the offline world (Finkelhor and Asdigian, 1996; Schreck and Fisher, 2004). It remains unclear, however, whether or not parental guardianship matters in online environments. A small but growing body of literature on parental monitoring in cyberspace has produced mixed findings on the effectiveness of online parental guardianship (Bossler et al., 2012; Mesch, 2009; Leukfeldt, 2014; Sengupta and Chaudhuri, 2010). For example, the odds of cyberbullying appears to be smaller when parents have well-established rules for visiting certain websites (Mesch, 2009). Conversely, adolescents whose parents installed protection software on the home computer were more at risk for experiencing online harassment (Bossler et al., 2012). Indeed, the most efficient online guardians may be programs that restrict Internet use to be effective online guardians (though these programs rarely apply to SNSs; Navarro and Jasinski, 2012). Further, parental guardianship on sexting has found that parents have a minimal deterrent effect on their teenagers sending and receiving sext messages (Martinez-Prather and Vandiver, 2014; Schreck and Fisher, 2004). Still other researchers have observed no significant relationship between parental monitoring and online victimization (Moore et al., 2010). Therefore, the role of parents as online guardians remains uncertain in existing research.

In the face of mixed results about parental guardianship in existing research, we relied upon our theoretical framework (Routine Activities Theory; Cohen and Felson, 1979) to develop our third hypothesis. Within a RAT framework, parents may limit the ability of adolescents to engage in online behaviors that may increase one's risk of online victimization. For example, Martinez-Prather and Vandiver (2014) found participants sent and received fewer sext messages if their parents had restrictions, monitored their cell phone use, and spend more time with their children. Conversely, adolescents who participate online privately, or in the absence of parental guardians, were more likely to experience cyberbullying (Sengupta and Chaudhuri, 2010). Further, in offline environments, the presence of a guardian would be expected to discourage motivated offenders from engaging in crime until the guardian is incapacitated or removed (Cohen and Felson, 1979). If this were applied to online environments, then, we would expect that parental monitoring and supervision would attenuate the hypothesized relationships between an adolescent's SNS behavior and online harassment.

H3: Parental guardianship on SNSs will moderate the relationship between SNS behaviors and online harassment.

\section{Methods}

\subsection{Data}

The current study used data with adolescent-parent dyads from the Pew Research Center's 2014 Teen Relationship Survey (TRS) to investigate the relationship between adolescent's SNS behaviors and the moderating effects of parents on online harassment(The data used for this study was gathered by a data-driven, nonpartisan research agency that conducts public opinion polls, demographic research, and social trend analysis for use in social scientific research.). The TRS contains self-report questions about teenagers' use of technology to interact with peers, romantic partners, and friends. The TRS also includes questions for the teenager's parents regarding their own SNS use, their monitoring behaviors, and the way they talk to their teens about appropriate online behavior.

\subsection{Sample}

The final sample included adolescents $(\mathrm{N}=351)$ and one of their parents or legal guardians $(\mathrm{N}=351$; see Table 1). The adolescent sample consisted mostly of females (n = 197). Of these adolescents, 97 were cell phone owners, 254 owned a smartphone, and 295 were Facebook users. The parent sample was comprised of 159 fathers and 192 mothers, of which 292 were Facebook users. Parental educational attainment ranged from high school or less (n $=122)$ to some college $(n=103)$ and a college or graduate degree $(n=126)$. We excluded 580 respondents from the initial sample of 1,638 due to lack of participation in the survey, and an additional 356 respondents who reported 
Table 1. Sample descriptive profile $(\mathrm{N}=351)$

\begin{tabular}{|c|c|c|c|c|c|c|}
\hline Variable & $\mathrm{f}$ & $\%$ & $\mathrm{M}$ & SD & Min & $\operatorname{Max}$ \\
\hline \multicolumn{7}{|c|}{ Adolescent Variables } \\
\hline Age & & & 15.21 & 1.39 & 13 & 17 \\
\hline \multicolumn{7}{|l|}{ Race } \\
\hline White & 227 & 64.7 & & & & \\
\hline Black & 37 & 10.5 & & & & \\
\hline Hispanic & 87 & 24.8 & & & & \\
\hline \multicolumn{7}{|l|}{ Sex } \\
\hline Male & 154 & 43.9 & & & & \\
\hline Female & 197 & 56.1 & & & & \\
\hline \multicolumn{7}{|c|}{ Parent Variables } \\
\hline Age & & & 45.01 & 8.19 & 26 & 68 \\
\hline \multicolumn{7}{|l|}{ Race $^{a}$} \\
\hline White & 229 & 65.24 & & & & \\
\hline Black & 39 & 11.11 & & & & \\
\hline Hispanic $^{3}$ & 75 & 21.08 & & & & \\
\hline \multicolumn{7}{|l|}{ Sex } \\
\hline Father & 159 & 45.3 & & & & \\
\hline Mother & 192 & 54.7 & & & & \\
\hline
\end{tabular}

not using any social media platform.

Table 2. Descriptive statistics $(\mathrm{N}=351)$

\begin{tabular}{|c|c|c|c|c|c|c|}
\hline Variable & $\mathrm{f}$ & $\%$ & $\mathrm{M}$ & SD & Min & $\operatorname{Max}$ \\
\hline \multicolumn{7}{|l|}{ Dependent Variable } \\
\hline Online Harassment & 129 & 36.75 & & & & \\
\hline \multicolumn{6}{|l|}{ Adolescent Variables } & 17 \\
\hline \multicolumn{7}{|l|}{ Race } \\
\hline White & 227 & 64.7 & & & & \\
\hline Black & 37 & 10.5 & & & & \\
\hline Hispanic & 87 & 24.8 & & & & \\
\hline \multicolumn{7}{|l|}{ Sex } \\
\hline Male & 154 & 43.9 & & & & \\
\hline Female & 197 & 56.1 & & & & \\
\hline Facebook Profile & 295 & 84.05 & & & & \\
\hline \multicolumn{7}{|l|}{ Device } \\
\hline No & 17 & 4.84 & & & & \\
\hline Yes & 334 & 95.16 & & & & \\
\hline \multicolumn{7}{|l|}{$\begin{array}{l}\text { Met Friends Online } \\
\text { (None) }\end{array}$} \\
\hline One & 22 & 6.27 & & & & \\
\hline Two-Five & 86 & 24.5 & & & & \\
\hline Five+ & 118 & 33.62 & & & & \\
\hline Sexted & 42 & 11.97 & & & & \\
\hline Interacted & 243 & 69.23 & & & & \\
\hline Friended & 246 & 70.09 & & & & \\
\hline $\begin{array}{l}\text { Friended upon } \\
\text { Suggestion }\end{array}$ & 99 & 28.21 & & & & \\
\hline Network Size & & & 246.82 & 482.48 & 0 & 5000 \\
\hline
\end{tabular}

\subsection{Variables}

\subsubsection{Online harassment}

Harassment that takes place via cyberspace might not always meet the status of being criminal, but the effects on the victims can be just as severe. Therefore, in this study, we used Jones and colleague's (2013) conceptualization of online harassment for our dependent variable, "as threats or other offensive behavior targeted directly at youth through [social media]" (p. 54). Seven items from the adolescent sample in the TRS were used to create a dichotomous incidence measure of SM harassment (see Table 2). The first item used in the measurement of SM harassment asked respondents, "While online have you ever unfriended or blocked someone who was flirting with you in a way that made you feel uncomfortable?" The next six items used to create the dependent variable begins with, "Has your current or former boyfriend, girlfriend, significant other, or person you are dating or hooking up with ever done any of the following..." The next six items completed the question: "...used information posted on the Internet against you to harass or embarrass you, used the Internet to try to pressure you into sexual activity you did not want to have, to spread rumors about you on the Internet, contacted you on the Internet to threaten to hurt you, and demanded to know the passwords to your email and Internet accounts?" Responses to each of the seven items were binary - yes (1) or no (0). The final outcome measure indicated whether or not the adolescent reported an experience with any of the seven victimization measures. Over a third of our adolescents reported at least one form of online harassment.

\subsubsection{Internet-accessible device}

Smartphones and other Internet-accessible devices allow constant access to the Internet. Additionally, Mesch (2009) found that adolescents who interact more often via their cell phone have an increased risk of cybervictimization. Thus, we included a measure for having easy, constant, and mostly private access to the Internet via a personal smartphone or tablet. Two items were used to create a single binary composite variable to measure frequent online access via an Internet accessible device. The items asked respondents, "Do you, personally, have or have access to each of the following items, or not. Do you have...a) a smartphone, b) a tablet?" Adolescents who reported having at least one of these Internet accessible devices were scored a one while all others were scored zero.

\subsection{Facebook profile}

The large number of Facebook members creates opportunities for offenders by providing them access to millions of potential targets. The item used to measure Facebook membership asked participants, "Which of the following social media do you use, Facebook?" Only those who answered either yes (1) or no (0) to Facebook were included in the current study; all other social media platforms were excluded.

\subsection{Control variables}

Age has been included consistently in research on cybervictimization, though scholars have found contradictory results. Past research has found that older adolescents are more likely to be harassed while participating online than younger adolescents (Mesch, 2009; Moore et al., 2010). In contrast, Navarro and Jasinski (2011) found 
that younger adolescents are more likely to be cyberbullied than older adolescents. The differences in these results might vary because past research has examined various types of cybercrime victimization. For example, scholars have sought to understand the correlates of cyberbullying (Tokunaga, 2010); online harassment through email, chatrooms, and instant messages (Mesch, 2009), cyberstalking (Reyns et al., 2011); and cybervictimization (Oksanen and Keipi, 2013). The adolescent's age was recorded in years and ranged from 13 to 17.

Additionally, existing research has found that sex may also predict online harassment. Female adolescents who participate in cyberspace (i.e., chat rooms, blogs, SNSs, etc.) have been more likely to receive unwanted contact, sexual advances, and online harassment than their male counterparts (Mesch, 2009; Moore et al., 2010; Navarro and Jasinski, 2012; Oksanen and Keipi, 2013; Reyns et al., 2011; Reyns et al., 2016; Sengupta and Chaudhuri, 2010). Sex was measured dichotomously, with males serving as our reference category $(0 ;)$. Finally, we created two dummy variables to indicate whether or not the adolescent identified as Black or Hispanic. White respondents were used as the reference category.

\subsection{Adolescent variables}

Adolescents may use SNSs to flirt, sext, and build their online network (Horstmanshof and Power, 2005; Hudson et al., 2014; Lenhart, 2009). Thus, we included measures for these online behaviors in our analyses. To measure the size of the participant's Facebook network, we used one item that asked respondents, "How many friends do you have on Facebook?" The participant's self-reported number of people in their network was measured as a continuous variable. Additionally, we used one item as a measure for meeting friends online. This item asked participants, "How many new friends, if any, have you made online?" Responses included meeting zero (0), one (1), two to five (2), and five or more (3) friends online.

The TRS included 5 items that addressed sexting and interacting via SNS. The first item used to measure the adolescent's romantic behaviors asked respondents, "Have you ever liked, commented or otherwise interacted with them on social media to let someone know you were attracted to them or interested in them?" The next three items began by asking participants, "To let someone know you were attracted to them or interested in them have you ever...". The question was followed by three activities participants were asked about including, "sent flirtatious messages," "sent them sexy or flirty pictures or videos of yourself," and "friended them on Facebook or another social network." The last item asked participants, "Have you ever 'followed' or 'friended' someone because one of your friends suggested you might want to date that person?" Participant's responses were either yes (1) or no (0). These items measure adolescents engaging strangers rather than being sought out by a stranger increasing their suitability as a target. Further, these items speak to the building and composition of one's online network.

\subsection{Parental guardianship variables}

We used six items from the TRS to explore the moderating effects of parents on online harassment. Of these six items, three were included because they speak to the parents ability to monitor their adolescent's online behaviors. The parental monitoring items measured access to an Internet-accessible device, SNS activity, and network size for parents. These items were measured in the same way as adolescents.In addition to asking parents about having a Facebook profile, though, the TRS also asked parents if they were friends with their child on Facebook. Response options for these items were yes (1) and no (0).

Past research has also assessed the effectiveness of parental guardianship by measuring their limitations on computer use. But many adolescents have smartphones that allow frequent and easy access to their SNS profiles. Thus, we used one item to measure whether they were able to monitor their adolescent's SNS behaviors through their cell phone rather than on a computer. This item asked parent participants, "Do you happen to know [teen's name] password for their cell phone?" This variable had two response categories - yes (1) and no (0).

To better understand parents' guardianship abilities, we also included items related to their monitoring behaviors. To measure parental monitoring, we used five items that asked parent respondents about ways they monitor their child's online participation. Parents were asked if they ever did the following: used parental controls or other means of filtering online activities, checked which websites their child visits, checked their child's SNS profile, takes cell phone or Internet privileges as a form of punishment, or limits the amount of time their child can spend online. Each question was answered either yes (1) and no (0).

Mesch (2009) found that the odds of cyberbullying decreased among participants whose parents had established rules for visiting certain websites. This may suggest that talking to children about the risk of online behaviors influences online harassment. Thus, we included an index score of parental talk in the analyses. These items inquired about how frequently they talk about the appropriateness and inappropriateness of online behavior toward others, sharing online, viewing content, and behavior in 
Table 3. Binary logistic regression of online harassment on SNS activity and parental guardianship

\begin{tabular}{|c|c|c|c|c|c|c|c|c|c|}
\hline \multirow{2}{*}{ Variable } & \multicolumn{3}{|c|}{$\begin{array}{l}\text { Model } 1 . \\
\text { Full Model with No Interactions }\end{array}$} & \multicolumn{3}{|c|}{$\begin{array}{c}\text { Model } 2 . \\
\text { Facebook Friends x Parental Monitoring }\end{array}$} & \multicolumn{3}{|c|}{$\begin{array}{l}\text { Model } 3 . \\
\text { Facebook Friends x Parental Talk }\end{array}$} \\
\hline & $\mathrm{b}$ & SE & OR & $\mathrm{b}$ & SE & OR & $\mathrm{b}$ & SE & OR \\
\hline \multicolumn{10}{|l|}{ Adolescent Variables } \\
\hline Age & -0.11 & 0.09 & 0.89 & 0.01 & 0.10 & 1.01 & 0.01 & 0.10 & 1.01 \\
\hline \multicolumn{10}{|l|}{ Race (White) } \\
\hline Black & 0.08 & 0.41 & 1.09 & 0.01 & 0.43 & 1.01 & 0.12 & 0.44 & 1.13 \\
\hline Hispanic & 0.43 & 0.27 & 1.54 & 0.38 & 0.30 & 1.47 & 0.44 & 0.30 & 1.55 \\
\hline Sex & 1.32 & 0.24 & $3.74 *$ & 1.11 & 0.27 & $3.03 *$ & 1.04 & 0.27 & $2.84 *$ \\
\hline Internet Accessible Device & 0.04 & 0.42 & 1.04 & 0.12 & 0.64 & 1.13 & 0.18 & 0.64 & 1.20 \\
\hline Meet Strangers Online & 0.33 & 0.09 & $1.39 *$ & 0.30 & 0.10 & $1.35^{*}$ & 0.28 & 0.11 & $1.32 *$ \\
\hline Sexting & 1.22 & 0.39 & $3.39 *$ & 0.97 & 0.41 & $2.65^{*}$ & 0.99 & 0.42 & $2.70^{*}$ \\
\hline Liked SNS Users & 0.50 & 0.32 & 1.65 & 0.62 & 0.35 & $1.86+$ & 0.53 & 0.36 & 1.70 \\
\hline Friended SNS Users & 0.75 & 0.33 & $2.13^{*}$ & 0.66 & 0.37 & $1.94+$ & 0.71 & 0.37 & $2.05+$ \\
\hline Connected with SNS Users & 0.71 & 0.27 & $2.05^{*}$ & 0.71 & 0.29 & $2.03 *$ & 0.77 & 0.30 & $2.16 *$ \\
\hline Number of Facebook Friends & $<0.01$ & $<0.01$ & $1.01+$ & $<0.01$ & $<0.01$ & $1.01+$ & $<0.01$ & $<0.01$ & $1.01+$ \\
\hline \multicolumn{10}{|l|}{ Parent Variables } \\
\hline Facebook User & -0.19 & 0.41 & 0.82 & -0.36 & 0.44 & 0.69 & -0.34 & 0.45 & 0.71 \\
\hline Friends with Adolescent & 0.36 & 0.33 & 1.44 & 0.43 & 0.38 & 1.54 & 0.39 & 0.38 & 1.48 \\
\hline Parental Talk & 0.19 & 0.13 & 1.21 & 0.28 & 0.15 & $1.33+$ & 0.28 & 0.15 & $1.33+$ \\
\hline Facebook Friends x Parental Monitoring & - & - & - & $<0.01$ & $<0.01$ & $1.01 *$ & - & - & - \\
\hline Facebook Friends x Parental Talk & - & - & - & - & - & - & $<0.01$ & $<0.01$ & 1.01 \\
\hline
\end{tabular}

social lives. Each of these items were scored in a 4-point Likert scale with more positive scores indicating more frequent protective talk. We generated an index score from these using a principal components analysis (Acock, 2018). Parental monitoring and parental talk were also used to create multiplicative interaction terms in the moderation analysis.

\section{Results}

\subsection{Model 1: SNS behaviors and online ha- rassment}

The current study examined two research questions. The first was to explore the relationship between an adolescent Facebook user's SNS behaviors and online harassment. Due to the dichotomous nature of the dependent variable we used binary logistic regression(Prior to running the primary logistic regression, we ran a series of diagnostics to ensure four assumptions of logistic regression were not violated - influential cases, normally distributed residuals, multicollinearity, and model specification. Diagnostics indicated that our models did not violate any of these assumptions.) (Acock, 2018). Model 1 included online harassment as the dependent variable, adolescent demographics, adolescent online behaviors, and parental predictor variables. The overall results of Model 1 were statistically significant, $X^{2}(18)=144.91$, $\mathrm{p}<0.001$ (see Table 3 ), which supports a relationship between SNS behaviors and online harassment.

Congruent with previous literature, the results showed that network size was a statistically significant predictor of online harassment $(\mathrm{OR}=1.01, \mathrm{p}<0.05)$. This means that the more Facebook friends adolescents had in their SNS network, the more likely they were to experience online harassment. Additionally, we found support for our second hypothesis, which claimed online harassment will be more likely amongst those who make new friends online $(\mathrm{OR}=1.40, \mathrm{p}<0.05)$. Model 1 also explored the relationship between online harassment and sexting, adding people because of romantic interest, and interacting with strangers. We found that adding strangers because of romantic interest $(\mathrm{OR}=2.13, \mathrm{p}<0.05)$ and interacting with strangers $(\mathrm{OR}=2.05, \mathrm{p}<0.05)$ significantly predicted online harassment. Additionally, sexting via social media increased the odds of online harassment nearly 4 times $(\mathrm{OR}=3.40, \mathrm{p}<0.05)$. Of the remaining adolsecent predictors in Model 1, the only significant predictors were having a Facebook profile and sex. Specifically, the results indicated that having a Facebook profile had a marginally significant and negative impact on online harassment $(\mathrm{OR}=0.46, \mathrm{p}<0.10)$. Consistent with prior research, the results revealed the odds of females experiencing online harassment are nearly 4 times more likely than male adolescents $(\mathrm{OR}=3.75, \mathrm{p}<0.001)$. The parental variables were not significant in Model 1.

\subsection{Interaction models of parental guardian- ship on Facebook network size}

Secondly, we assessed the moderation effect for two of our parental guardianship variables on adolescent risk of online harassment using binary logistic regression. Models 2 through 7 included a multiplicative interaction term for parental guardianship: adolescent network size $\mathrm{x}$ parental talk, adolescent network size $\mathrm{x}$ parental 
monitoring, adolescent sex x parental monitoring, adolescent sex x parental talk, meeting new friends online $\mathrm{x}$ parental monitoring, and meeting new friends online $\mathrm{x}$ parental talk. Each regression included a single parent-byadolescent interaction term at a time to avoid introducing multicollinearity into the model.

The only significant interaction effects were parental monitoring on the size of the adolescent's Facebook network $(\mathrm{OR}=1.001)$ and parental monitoring on a male adolescent's risk of online harassment $(\mathrm{OR}=1.38)$. As variety in parental monitoring increased, the effect of the number of friends one has on Facebook as a stronger, positive effect on online harassment (see Figure 1). The interaction effect became significant after three or more types of parental monitoring.

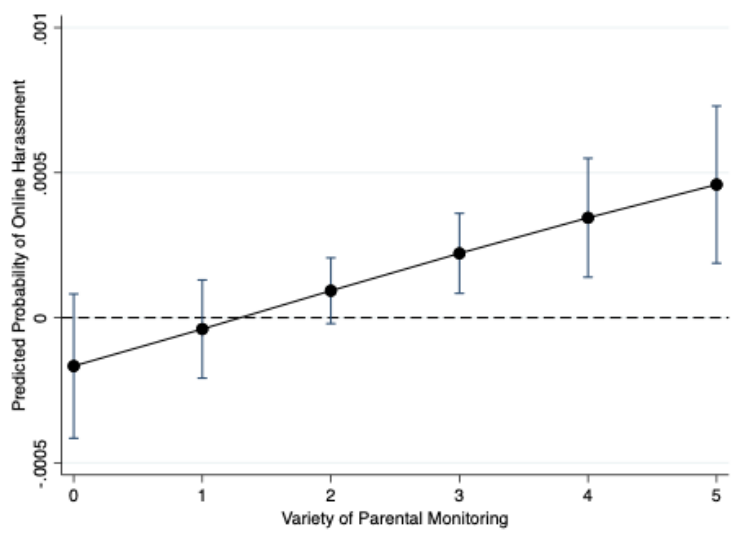

Figure 1. Interaction of parental monitoring on network size and online harassment

The sex effect on online harassment is only present at higher variety of parental monitoring. Male and female adolescents are no different in reported harassment when their parents use fewer monitoring approaches (see Table 4). Our results indicated that parental monitoring works differently for male and female adolescents (see Figure 2). Namely, whereas the probability of harassment declines with more diverse monitoring of male adolescents, harassment increases with more varied monitoring of female adolescents. This finding lends some support to Mesch's (2009) finding that when parents implement rules on Internet use and monitor the websites used, male adolescent's risk of online bullying decreased. Neither of the interaction terms representing the moderation effect of parental guardianship on meeting strangers offline were significant (see Table 5). Consequently, our results demonstrated mixed support for our third hypothesis.

\section{Discussion}

The purpose of this study was threefold. First, we aimed to investigate the relationship between an ado-

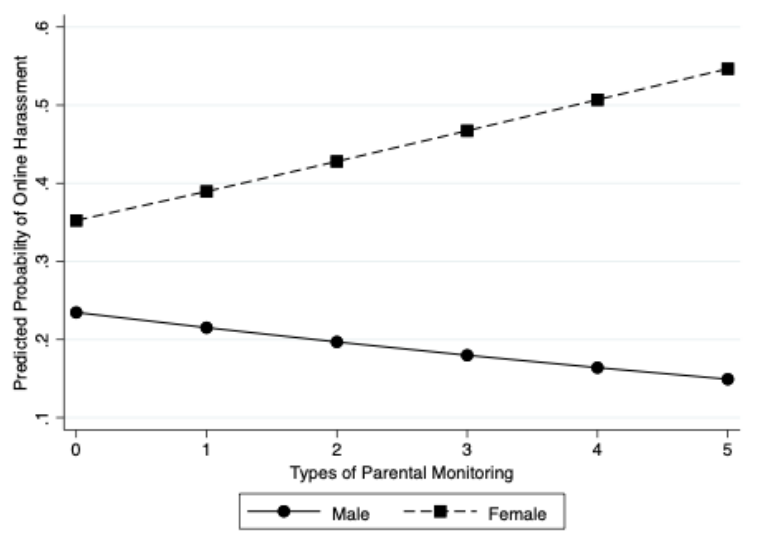

Figure 2. Interaction Effect of Parental Monitoring on Sex and Online Harassment

lescent Facebook user's SNS behaviors and online harassment. Overall, our findings revealed a statistically significant relationship between social media and online harassment. This means that social media users were at an increased risk of experiencing some form of harassment while participating on a SNS. However, this relationship warranted more exploration to identify specific correlates of online harassment, which was the second aim of our study. We found that respondents had greater odds of reporting victimization if they were female,had larger Facebook networks, met new friends online, sexted or flirted with others, or interacted with SNS users.

Although one purpose of SNSs is to make connections through online networks, our results revealed that the size and development of an online network can increase the risk of online victimization (Danah, 2011; Haythornthwaite, 2005). Further, we found that the interactions that take place on a SNS and within an adolescent's network can also impact the risk of online victimization. Moreover, the high proportion of respondents in our sample that reported flirting and sexting via a SNS might suggest a general unawareness of the risks of SNS participation and of risky SNS behaviors among adolescents. These findings can be used to promote awareness about the risk involved in having large SNS networks and certain online behaviors and interactions. Through awareness and educational programs, adolescents may begin to see large networks as a risk rather than a way to build self-esteem or an outlet for self-promotion.

In the RAT framework, opportunity for victimization can be expected when a motivated offender has access to a suitable target in the absence of capable guardians (Cohen and Felson, 1979). Offender motivation is largely left to other criminological theories by RAT models. Therefore, two remaining interpretations might include target suitability (access or vulnerability) and the presence of guardians (such as parents or bystanders).One pos- 
Table 4. Sex x parenting interactions

\begin{tabular}{|c|c|c|c|c|c|c|}
\hline \multirow{2}{*}{ Variable } & \multicolumn{3}{|c|}{$\begin{array}{c}\text { Model } 4 . \\
\text { Sex x Parental Monitoring }\end{array}$} & \multicolumn{3}{|c|}{$\begin{array}{c}\text { Model } 5 . \\
\text { Sex x Parental Talk }\end{array}$} \\
\hline & $\mathrm{b}$ & SE & OR & $\mathrm{b}$ & SE & OR \\
\hline \multicolumn{7}{|l|}{ Adolescent Variables } \\
\hline Age & 0.040 & 0.102 & 1.041 & 0.005 & 0.102 & 1.005 \\
\hline \multicolumn{7}{|l|}{ Race (White) } \\
\hline Black & -0.016 & 0.439 & 0.984 & 0.012 & 0.439 & 1.012 \\
\hline Hispanic & 0.424 & 0.305 & 1.529 & 0.388 & 0.305 & 1.474 \\
\hline Sex & 0.121 & 0.577 & 1.129 & 1.103 & 0.271 & $3.012 *$ \\
\hline Facebook User & -0.783 & 0.454 & $0.457+$ & -0.986 & 0.464 & $0.373 *$ \\
\hline Internet Accessible Device & 0.178 & 0.642 & 1.194 & 0.109 & 0.647 & 1.115 \\
\hline Meet Strangers from Web & 0.315 & 0.108 & $1.371 *$ & 0.301 & 0.109 & $1.351^{*}$ \\
\hline Sexting & 0.961 & 0.415 & $2.615^{*}$ & 0.979 & 0.415 & $2.663^{*}$ \\
\hline Liked SNS Users & 0.699 & 0.361 & $2.011+$ & 0.625 & 0.359 & $1.867+$ \\
\hline Friended SNS Users & 0.562 & 0.378 & 1.754 & 0.665 & 0.377 & $1.944+$ \\
\hline Connected with SNS Users & 0.660 & 0.298 & $1.936^{*}$ & 0.698 & 0.301 & $2.010 *$ \\
\hline Number of Facebook Friends & 0.001 & $<0.001$ & $1.001+$ & 0.001 & $<0.001$ & $1.001+$ \\
\hline \multicolumn{7}{|l|}{ Parent Variables } \\
\hline Facebook User & -0.436 & 0.447 & 0.646 & -0.384 & 0.448 & 0.681 \\
\hline Friends with Adolescent on Facebook & 0.443 & 0.384 & 1.557 & 0.449 & 0.383 & 1.566 \\
\hline Mobile Device & -0.048 & 0.488 & 0.953 & -0.111 & 0.489 & 0.895 \\
\hline Parental Monitoring & -0.155 & 0.152 & 0.857 & 0.048 & 0.100 & 1.049 \\
\hline Parental Talk & 0.281 & 0.154 & $1.324+$ & 0.246 & 0.222 & 1.278 \\
\hline Sex x Parental Monitoring & 0.324 & 0.182 & $1.382+$ & - & - & - \\
\hline Sex x Parental Talk & - & - & - & 0.081 & 0.279 & 1.085 \\
\hline
\end{tabular}

sible source for both of these interpretations could be parents. The 2014 Pew TRS data included adolescentparent dyads, which allowed us to include both parental monitoring and socialization in our models. The results demonstrated that parental monitoring moderated some of an adolescent's risk of online harassment. We suspected that parents who attempted to train their adolescents to be more cautious in their online activities would encourage target hardening. Additionally, parents who were more actively engaged in their adolescent's online activities, either as a viewer or an obstacle, might attenuate risk of victimization established at the adolescent level. Although adolescent risk of victimization was not conditioned by parental attempts at socialization, focused attempts at parental monitoring did attenuate the riskiness associated with large Facebook networks. These findings may suggest that lessons learned from conversations with parents were less effective at reducing an adolescent's existing risk of online harassment than direct involvement. That said, due to limitations in both the time order and details in these variables (e.g., methods for establishing the parent's presence online), additional research is still needed to clarify the role of parental guardianship in online settings.

Adolescent activity online has the most direct relationship with online harassment. Therefore, we may be able to curb the risk of online harassment by educating adolescents about risky online behaviors and security features available to them. The limited role of parents in this analysis should not be taken to mean that parental online behaviors are irrelevant. Rather, this analysis may help parents to reconsider and tailor their approach to online guardianship. For example, parents may have more impact through more direct guardianship (e.g., monitoring rather than talk/preparation). However, there is also an argument for "doing more with less" in monitoring tactics, especially with adolescent girls. Limitations and Implications

The results provided evidence of the existence of this relationship and identified specific behaviors that increase the risk of online harassment, but this study is not without limitations. Lesbian, gay, bisexual, transgender, and questioning (LGBTQ) adolescents were not included in the analysis due to the small number of participants. Also, Black participants were underrepresented in this study. LGBTQ and non-White teens have been identified as a common target of online harassment which warrants future research (Hinduja and Patchin, 2011; Ngo and Paternoster, 2011). Future research that includes a more diverse sample of adolescents will further our understanding of online harassment and the role of social media behaviors.

The speed at which data on social media can change makes keeping research current difficult. This study only included adolescents who used Facebook. However, Facebook has dropped in popularity among adolescents since the 2014 Teen Relationship Survey. Today, Snapchat, Instagram, and YouTube are among the most popular social media sites among adolescents (Anderson and Jiang, 2018).

The novelty of social media limits the data available to students and scholars. Collecting data that helps to better distinguish between the various types of social media behaviors, would broaden our knowledge base of SNS 
Table 5. Meeting strangers $x$ parenting interactions

\begin{tabular}{|c|c|c|c|c|c|c|}
\hline \multirow{2}{*}{ Variable } & \multicolumn{3}{|c|}{$\begin{array}{l}\text { Model 6. Meeting Strangers } \\
\text { x Parental Monitoring }\end{array}$} & \multicolumn{3}{|c|}{$\begin{array}{c}\text { Model 7. Meeting Strangers } \\
\text { x Parental Talk }\end{array}$} \\
\hline & $\mathrm{b}$ & SE & OR & $\mathrm{b}$ & SE & OR \\
\hline \multicolumn{7}{|l|}{ Adolescent Variables } \\
\hline Age & 0.011 & 0.103 & 1.011 & 0.021 & 0.102 & 1.021 \\
\hline \multicolumn{7}{|l|}{ Race (White) } \\
\hline Black & -0.041 & 0.445 & 0.96 & 0.003 & 0.441 & 1.003 \\
\hline Hispanic & 0.369 & 0.312 & 1.446 & 0.332 & 0.31 & 1.393 \\
\hline Sex & 1.226 & 0.281 & $3.408^{*}$ & 1.176 & 0.277 & $3.243^{*}$ \\
\hline Facebook User & -0.886 & 0.468 & $0.412+$ & -0.934 & 0.468 & $0.393^{*}$ \\
\hline Internet Accessible Device & 0.174 & 0.664 & 1.19 & 0.188 & 0.661 & 1.207 \\
\hline Meet Strangers from Web & 0.418 & 0.218 & $1.519+$ & 0.301 & 0.11 & $1.351^{*}$ \\
\hline Sexting & 0.945 & 0.422 & $2.573 *$ & 0.928 & 0.425 & $2.529 *$ \\
\hline Liked SNS Users & 0.713 & 0.368 & $2.039+$ & 0.702 & 0.365 & $2.018+$ \\
\hline Friended SNS Users & 0.682 & 0.38 & $1.977+$ & 0.706 & 0.38 & $2.026+$ \\
\hline Connected with SNS Users & 0.703 & 0.303 & $2.020^{*}$ & 0.693 & 0.301 & $2.000^{*}$ \\
\hline Number of Facebook Friends & 0.001 & $<0.001$ & $1.001+$ & 0.001 & $<0.001$ & $1.001+$ \\
\hline \multicolumn{7}{|l|}{ Parent Variables } \\
\hline Facebook User & -0.206 & 0.452 & 0.814 & -0.327 & 0.451 & 0.721 \\
\hline Friends with Adolescent on Facebook & 0.295 & 0.387 & 1.342 & 0.376 & 0.388 & 1.457 \\
\hline Mobile Device & -0.125 & 0.507 & 0.883 & -0.111 & 0.501 & 0.895 \\
\hline Parental Monitoring & 0.019 & 0.16 & 1.02 & 0.044 & 0.101 & 1.045 \\
\hline Parental Talk & 0.316 & 0.158 & $1.372 *$ & 0.327 & 0.286 & 1.387 \\
\hline \multicolumn{7}{|c|}{ Meeting Strangers (None) x Parental Monitoring } \\
\hline One & 0.156 & 0.346 & 1.168 & - & - & - \\
\hline Two to Five & 0.217 & 0.228 & 1.243 & - & - & - \\
\hline Five or More & -0.121 & 0.207 & 0.886 & - & - & - \\
\hline \multicolumn{7}{|l|}{ Meeting Strangers x Parental Talk } \\
\hline One & - & - & - & 0.024 & 0.62 & 1.024 \\
\hline Two to Five & - & - & - & -0.056 & 0.359 & 0.945 \\
\hline Five or More & - & - & - & 0.018 & 0.36 & 1.018 \\
\hline
\end{tabular}

Note: ${ }^{*}=\mathrm{p}<0.05{ }^{+}=\mathrm{p}<0.10$; Reference categories in parentheses

online harassment. For example, if an adolescent liberally adds strangers to their SNS network but does not have personal information posted and does not communicate with strangers might not be at risk for victimization.

Despite these limitations, our research identified certain behaviors that increase the risk of online harassment, which hold implications for future efforts to reduce cybervictimization, especially from parents and educators. In accordance with RAT, which has been demonstrated to be useful for explaining cybercrime rates (Leukfeldt, 2014; Reyns et al., 2011), our findings suggest that guardianship and target hardening that originates with adults may be able to deflect opportunities to victimize adolescents online in a limited way. Consequently, an implication (and future research direction) may be that guardianship and target hardening should come from the adolescents. Indeed, adolescents might prove to be their own most effective guardian by using caution taking steps to become better prepared for attacks online.

Although the findings did not provide evidence that parents demonstrated capable guardianship by just being on Facebook, parents may be able to help reduce their child's suitability as a target of harassment based on this study's findings. For example, parents can use this information to teach their adolescents to use caution when developing their online networks. Additionally, the findings help educators and parents understand the behaviors that increase the risk of victimization, which can allow them to better educate adolescents about risky SNS behaviors.
This study also adds to existing literature using the RAT framework to understand online victimization. Though there was support for the concept of suitable targets, the role of capable guardians needs additional research.

The results showed that parental monitoring had different moderating effects on risk of online harassment for male and females. As adolescents are participating on the same SNS, differences in females and males behavior on social media likely play a role in victimization risks. Future research should delve deeper into the relationship between gender and social media victimization. The ineffectiveness of parents on social media might be specific to Facebook given that adolescents use Snapchat, Instagram, and YouTube more frequently (Anderson and Jiang, 2018). Future research would benefit from examining parental guardianship on other SNS platforms. As parents understand their influence on social media they may begin to find alternative ways of protecting their teens online. Online harassment is unlike traditional criminal events where parents do have the ability to be effective guardians (Finkelhor and Asdigian, 1996).

\section{Conclusion}

Online harassment cannot be combated in the same manner as traditional crime. As deviant and criminal behavior takes place online, victims can experience a wide variety of negative repercussions, ranging from decreased self-esteem to becoming suicidal. Public awareness of 
the repercussions and risky behaviors that connect to online harassment is critical for lowering rates of online harassment. The novelty and rapid evolution of SNSs make it difficult to comprehensively study this popular form of online participation. As a field of research still in its infancy, there has been little information available to the public and practitioners to make them aware of the benefits and risks of online socialization. As a result, parents have few resources to educate their teenagers on appropriate social media behaviors. Further, teenagers heavily engaged in SNS networks may be unintentionally inviting risk. This line of research was important to learn more about risky SNS behaviors and, through public awareness and interventions, contribute to reduced online victimization rates.

\section{References}

Acock AC, 2018. A gentle introduction to Stata (6th Ed.). College Station, TX: Stata Press.

Anderson Jiang, 2018. Teens, Social Media \& Technology 2018 YouTube, Instagram and Snapchat are the most popular online platforms among teens. Fully $95 \%$ of teens have access to a smartphone, and $45 \%$ say they are online 'almost constantly'. Washington, DC: Pew Research Center.

Arntfield M. Toward a cybervictimology: Cyberbullying, routine activities theory, and the anti-sociality of social media. Canadian Journal of Communication, 2015, 40(3): 371-388. https://doi.org/10.22230/cjc.2015v40n3a2863

Bergman SM, Fearrington ME, Davenport SW. et al. Millennials, narcissism, and social networking: What narcissists do on social networking sites and why. Personality and Individual Differences, 2011, 50(5): 706-711. https://doi.org/10.1016/j.paid.2010.12.022

Bossler AM, Holt TJ and May DC. Predicting online harassment victimization among a juvenile population. Youth \& Society, 2012, 44(4): 500-523. https://doi.org/10.1177/00448X11407525

Bossler AM and Holt TJ. On-line activities, guardianship, and malware infection: An examination of routine activity theory. International Journal of Cyber Criminology, 2009, 3(1): 400-420.

Carpenter CJ. Narcissism on Facebook: Self-promotional and anti-social behavior. Personality and Individual Differences, 2012, 52(4): 482-486. https://doi.org/10.1016/j.paid.2011.11.011

Choi K. Computer crime and victimization and integrated theory: An empirical assessment. International Journal of Cyber Criminology, 2008, 2(1): 308-322.

Cohen LE and Felson M. Social change and crime rate trends: A routine activity approach. American Sociological Review, 1979, 44: 588-608.

Danah B. Social network sites as networked publics affordances, dynamics, and implications. In Z. Papacharissi (Ed.), A networked self-identity, community, and culture on social network sites 39-54. New York, NY: Routledge, 2011.
Danah B and Ellison NB. Social network sites: Definition, history, and scholarship. Journal of Computer-Mediated Communication, 2008, 13(1): 210-230.

Dehue F, Bolman C and Vollink T. Cyberbullying: Youngsters' experiences and parent perception. CyberPsychology and Behavior, 2008, 11(2): 117-125. https://doi.org/10.1089/cpb.2007.0008

Desilver D. Overseas users power Facebook's growth; more going mobile-only. Washington, DC: Pew Research Center, 2014.

Duggan M. Online harassment 2017. Washington, DC: Pew Research Center, 2017.

Dwyer C, Hiltz SR and Passerini K. Trust and privacy concern within social networking sites: A comparison of Facebook and MySpace. Proceedings of the Thirteenth Americas Conference on Information Systems, USA, 2007, 13: 1-12.

Finkelhor D and Asdigian NL. Risk factors for youth victimization: Beyond a lifestyle/routine activities theory approach. Violence and Victims, 1996, 11(1): 3-20.

Haythornthwaite C. Social networks and internet connectivity effects. Information, Communication, and Society, 2005, 8(2): 125-147. https://doi.org/10.1080/13691180500146185

Hinduja S and Patchin JW. Cyberbullying and sexual orientation. Unknown: Cyberbullying Research Center, 2011.

Hollis ME, Felson M and Welsh BC. The capable guardian in routine activities theory: A theoretical and conceptual reappraisal. Crime Prevention and Community Safety, 2013, 15: 65-79. https://doi.org/10.1057/cpcs.2012.14

Holtfreter K, Reisig MD and Pratt TC. Low self-control, routine activities, and fraud victimization. Criminology, 2008, 46(1): 189-220. https://doi.org/10.1111/j.1745-9125.2008.00101.x

Horstmanshof L and Power MR. Mobile phones, SMS, and relationships. Australian Journal of Communication, 2005, 32: 33-52.

Hudson HK, Fetro JV and Ogletree R. Behavioral indicators and behaviors related to sexting among undergraduate students. American Journal of Health Education, 2014, 44(3): 183-195.

Hutchings A and Hayes H. Routine Activity Theory and phishing victimization: Who gets caught in the 'Net'? Current Issues in Criminal Justice, 2009, 20(3): 1-21. https://doi.org/10.1080/10345329.2009.12035821

Jelenchick LA, Eickhoff JC and Moreno MA. "Facebook Depression?" Social networking site use and depression in older adolescents. Journal of Adolescent Health, 2013, 52: 128-130. https://doi.org/10.1016/j.jadohealth.2012.05.008

Jones LM, Mitchell KJ and Finkelhor D. Online harassment in context: Trends from three Youth Internet Safety Surveys (2000, 2005, 2010). Psychology of Violence, 2013, 3(1): 5369. https://doi.org/10.1037/a0030309

Kalia D and Aleem S. Cyber victimization among adolescents: Examining the role of routine activity theory. Journal of Psychosocial Research, 2017, 12(1): 223-232. 
Lenhart A. Overview: Teens and sexting: How and why minor teens are sending sexually suggestive nude or nearly nude images via text messaging. Pew Internet and American Life Project, 2009.

Lenhart A, Madden M, Smith A, et al. Teens, kindness, and cruelty on social network sites how American teens navigate the new world of digital citizenship. Washington, DC: Pew Research Center, 2011. https://doi.org/10.1002/cyto.a.21149

Lenhart A, Smith A and Anderson M. Teens, technology, and romantic relationships. Washington, DC: Pew Research Center, 2015.

Leukfeldt ER. Phishing for suitable targets in The Netherlands: Routine activity theory and phishing victimization. Cyberpsychology, Behavior, and Social Networking, 2014, 17(8): 551-558. https://doi.org/10.1089/cyber.2014.0008

Livingstone S. Taking risky opportunities in youthful content creation: Teenagers' use of social networking sites for intimacy, privacy and self-expression. New Media and Society, 2008, 3(10): 393-411. https://doi.org/10.1177/1461444808089415

Madden M, Lenhart A, Cortesi S, et al. Teens, social media and privacy. Washington, DC: Pew Research Center, 2013. http://apo.org.au/node/34223

Mahatanankoon P and O'Sullivan P. Attitudes towards mobiletext messaging: An expectancy-based perspective. Journal of Computer-Mediated Communication, 2008, 13: 973-992. https://doi.org/10.1111/j.1083-6101.2008.00427.x

Marcum CD, Higgins GE and Ricketts ML. Juveniles and cyber stalking in the United States: An analysis of theoretical predictors of patterns of online perpetration. International Journal of Cyber Criminology, 2014, 8(1): 47-56. https://doi.org/US3535522 A

Martinez-Prather $\mathrm{K}$ and Vandiver DM. Sexting among teenagers in the United States: A retrospective analysis of identifying motivating factors, potential targets, and the role of a capable guardian. International Journal of Cyber Criminology, 2014, 8(1): 21-35.

Massimini $\mathrm{M}$ and Peterson M. Information and communication technology: Effects on U.S. college students. Cyberpsychology: Journal of Psychosocial Research on Cyberspace, 2009, 3(1): 3 .

Mesch GS. Parental mediation, online activities, and cyberbullying. CyberPsychology and Behavior, 2009, 12(4): 387396.

https://doi.org/10.1089/cpb.2009.0068

Moore R, Guntupalli NT and Lee T. Parental regulation and online activities: Examining factors that influence a youth's potential to become a victim of online harassment. International Journal of Cyber Criminology, 2010, 4(1 \& 2): 685698

Navarro JN and Jasinski JL. Going cyber: Using Routine Activities Theory to predict cyberbullying experiences. Sociological Spectrum, 2012, 32: 81-94. https://doi.org/10.1080/02732173.2012.628560

Ngo FT and Paternoster R. Cybercrime victimization: An examination of individual and situational level factors. International Journal of Cyber Criminology, 2011, 5(1): 773-793.
O'Keeffe GS and Clarke-Pearson K. The impact of social media on children, adolescents, and families. Pediatrics, 2011, 121(4): $120-127$.

https://doi.org/10.1542/peds.2011-0054

Oksanen A and Keipi K. Young people as victims of crime on the Internet: A population-based study in Finland. Vulnerable Children and Youth Studies, 2013, 8(4): 298-309.

Reyns BW, Henson B and Fisher BS. Being pursued online applying cyber lifestyle routine activities theory to cyberstalking victimization. Criminal Justice and Behavior, 2011, 38(11): 1149-1172.

Reyns BW, Henson B and Fisher BS. Guardians of the cyber galaxy: An empirical and theoretical analysis of the guardianship concept from routine activity theory as it applies to online forms of victimization. Journal of Contemporary Criminal Justice, 2016, 32(2): 148-168. https://doi.org/10.1177/1043986215621378

Rife SC, Cate KL, Kosinski M, et al. Participant recruitment and data collection through Facebook: The role of personality factors. International Journal of Social Research Methodology, 2013, 19(1): 69-83. https://doi.org/10.1080/13645579.2014.957069

Runions KC, Bak M and Shaw T. Disentangling functions of online aggression: The Cyber-Aggression Typology Questionnaire (CATQ). Aggressive Behavior, 2017, 43: 74-84. https://doi.org/10.1002/ab.21663

Ryan $\mathrm{T}$ and Xenos S. Who uses Facebook? An investigation into the relationship between the Big Five, shyness, narcissism, loneliness, and Facebook usage. Computers in Human Behavior, 2011, 27: 1658-1664. https://doi.org/10.1016/j.chb.2011.02.004

Schreck CJ and Fisher BS. Specifying the influence of family and peers on violent victimization. Journal of Interpersonal Violence, 2004, 19(9): 1021-1041.

Sengupta A and Chaudhuri A. Are social networking sites a source of online harassment for teens? Evidence from survey data. Children and Youth Services Review, 2010, 33: 284290.

https://doi.org/10.1016/j.childyouth.2010.09.011

Shaw AM, Timpano KR, Tran TB, et al. Correlates of Facebook usage patterns: The relationship between passive Facebook use, social anxiety symptoms, and brooding. Computers in Human Behavior, 2015, 45: 574-581. https://doi.org/10.1016/j.chb.2015.02.003

Smith A and Anderson M. Social media use in 2018. Washington, DC: Pew Research Center, 2018.

Smith PK, Mahdavi J, Carvalho M, et al. Cyberbullying: Its nature and impact in secondary school pupils. The Journal of Child Psychology and Psychiatry, 2008, 49(4): 376-385. https://doi.org/10.1111/j.1469-7610.2007.01846.x

Sullivan EM, Annest JL, Simon TR, et al. Suicide trends among persons aged 10-24 years United States, 1994-2012. Centers for Disease Control and Prevention, 2015, 64(8): 201-205.

Tandoc Jr EC, Ferrucci P and Duffy M. Facebook use, envy, and depression among college students: Is Facebooking depressing? Computers in Human Behavior, 2015, 43: 139-146. https://doi.org/10.1016/j.chb.2014.10.053 
The National Campaign, 2009. The National Campaign to Prevent Teen and Unplanned Pregnancy and CosmoGirl.com reveals results of Sex and Tech Survey: Large percentage of teens posting/sending nude/semi nude images. The National Campaign to Prevent Teen and Unplanned Pregnancy.

Tokunaga RS. Following you home from school: A critical review and synthesis of research on cyberbullying victimization. Computers in Human Behavior, 2010, 26: 277-287. https://doi.org/10.1016/j.chb.2009.11.014

Valkenburg PM, Peter J and Schouten AP. Friend networking sites and their relationship to adolescents' well-being and social self-esteem. CyberPsychology and Behavior, 2006, 9(5): 583-591.

https://doi.org/10.1089/cpb.2006.9.584

Ybarra ML and Mitchell KJ. How risky are social networking sites?: A comparison of places online where youth sexual solicitation and harassment occurs. Pediatrics, 2008, 121(2): 350-360. 